\title{
Youth-adult partnership and youth civic development: cross-national analyses for scholars and field professionals
}

\begin{abstract}
Across the world, community-based youth organizations are engaging youth as partners with adults to promote youth civic development. A sample of 528 youth from the United States, Portugal, and Malaysia were surveyed to explore associations between youth-adult partnership (youth voice in decision making; supportive adult relationships) and two key aspects of civic development (youth empowerment; community connections). Multi-level modeling, regression, and profile analysis were used to compare patterns of association across the three national samples. Results indicate that youth are most likely to achieve positive outcomes when they experience the freedom to make decisions, while experiencing trust and power sharing from adults. The results were consistent across the three national samples, suggesting that the influence of partnership may transcend cultures and contexts. Future scholarship should aim to support field professionals in building organizational structures and opportunities that encourage shared dialogue, program planning, and purposeful action among youth and adults.
\end{abstract}

Keyword: Youth-adult partnership; Youth civic development; Civic engagement; Crosscultural analysis; Extracurricular activity; Neighbourhood context 